\title{
Study on Performance of the Exhaust Valve in Water Supply and Drainage Engineering
}

\author{
Li Zhao ${ }^{1,2, a}$ Yusi Yang ${ }^{1, b}$ Yudong $\mathrm{Lu}^{1, \mathrm{c}}$ Xiao Hu ${ }^{1, \mathrm{~d}}$ Linghui Fan ${ }^{1, \mathrm{~d}}$
}

1 Chang'an University, School of Environmental Science and Engineering, China 710054

2 Xi'an Aeronautical University, Department of Power Engineering, China 710077

azhaoli200817@163.com, b22958531@qq.com, clyd@163.com,dhf123@163.com

\begin{abstract}
Key words:Press pipeline; Water hammer;Exhaust valve
Abstract. Gas cannot prompt emission is the main reason for Water pipeline burst, explore the exhaust valve's performance at present, which has practical significance for the pipeline safety protection.Through the experiment, research the commonly used exhaust valve in water supply and drainage engineering and comparison of theirs exhaust performance.Respectively summarizes the applicable conditions of the currently used exhaust valve.Gave performance evaluation for both at home and abroad exhaust valve. Thus solves the pipeline burst question because the gas cannot prompt emissions specially in long distance water distribution pipeline of actual project .
\end{abstract}

\section{Introduction}

With the existence of gas in the pipeline, it will cause a lot of harm if poor exhaust ${ }^{[1]}$. Tube-burst accident is likely to happen especially in the long distance water conveyance pipeline if there is still a lot of gas stay inside.

There's a lot of cases such as water-supply pipe exploding in Xuchang City, He'nan Provence, and it caused a great economic losses ${ }^{[2]}$. Therefore, it is necessary to research the water supply pipeline exhaust-problems in recent years. Currently, we adopt many ways to exhaust,for example, exhaust air shaft, manual exhaust valve, exhausting with range pipe or automatic air valve ${ }^{[3]}$. But the former three kinds of exhaust way has significant limitations, only the automatic air valve could exhaust the air in the pipe efficiently ${ }^{[4,5]}$.

As the exhaust effect of different kinds of exhaust valve has a very big difference, so it is very important for us to research the influence of the performance and structure of the exhaust valve on the pressure pipes. Based on the current domestic market of all kinds of exhaust valves, we research on their performance. During research process, we use the experimental method which simulate the gaswater two-phase flow of engineering projects to study the exhaust performance of various kinds of exhaust valves respectively. Then point out the both abroad and home exhaust valve's applicable conditions and evaluate their performance and provide some theoretical basis about the exhaust problem of long distance water conveyance.

Five different types of exhaust valve .The experimental test of five kinds of exhaust valve about the exhaust performance, such as Figure 2, respectively are double exhaust valve(type P2-10) ,compound double mouth exhaust valve (KP-10 type), foreign power type exhaust valve, leveraged exhaust valve,full pressure high speed cylinder type exhaust valve QSP1.0 type.

\section{Experimental process}

(1)Install the exhaust valve on the performance test station.

(2)Close all valves and inject some water into the air hydraulic cylinder, use air compressor to elevate pressure to $1.0 \mathrm{mpa}$.

(3)Adjust the constant pressure valve to get the experimental necessary value (we could use the release valve to reduce the needless pressure)

(4)Open the inlet valve and examine the exhaust situation when the dry air condition. If all outlet exhaust smoothly elevate the pressure until $1.0 \mathrm{mpa}$. 
(5)Close inlet valve and adjust constant pressure valve to the necessary value.Open water inlet valve to let some water in exhaust valve.Then close water inlet valve and open inlet valve, examine the exhaust situation with the condition of Mixed gas water flow. If all outlet could exhaust smoothly then retry and elevate pressure until 1.0 mpa .

(6)Close all valves and open water escape valve to release the water and air inside,then close the valve.Open water inlet valve until the balling-up. Examine the exhaust valve's closure situation and check whether it leak or not.

(7)Close inlet water valve and adjust constant pressure valve to make the pressure to experimental pressure. Open inlet valve and water escape valve at the same time. Then examine the exhaust situation of exhaust valve with the condition of Mixed gas water flow ( cylinder air-relief valve use result is good).

\section{Results of analysis}

A Comparative Analysis On Exhaust Valve's Performance.Roughly divide exhaust valve's performances into 7 categories according to experimental outcomes and practical engineering experience:

\section{(1)High-Efficiency Exhaust Valve}

The technical index of High-Efficiency Exhaust Valve is that the exhaust valve could exhaust smootly via its big and small exhaust ports as long as the air in the pipeline under any pressure and the big and small exhaust ports immediately close up when water enter exhaust valve,never leak.Meanwhile the effective exhaust diameter of both the big and small exhaust port or only the big one is no less than $70 \%-80 \%$ of exhaust valve's nominal diameter.Many water column and gas column in the pipe ,the valve is able to exhaust air at high speed when meet with air and close immediatly when meet water,it's also able to consistently exhaust air smoothly and at unlimited times.Pay attention to ensure a constant air pressure during the whole process of the experiment.

(2)Type I of Dynamic Exhaust Valve

Cannot exhaust smoothly in mixed gas water flow ,but exhaust effect is good under the dry air condition .

(3)Type II of Dynamic Exhaust Valve

Cannot exhaust smoothly in mixed gas water flow ,but exhaust effect is good when the mix water-air flow's pressure below 0.6mpa or high pressure dry air.

(4)Type I of Dry Air Exhaust Valve

Cannot exhaust smoothly in mixed gas water flow ,but exhaust effect is good under the dry air condition no matter how big the pressure is.

(5) Type II of Dry Air Exhaust Valve

Cannot exhaust smoothly in mixed gas water flow ,but exhaust effect is good when dry air pressure is below $0.6 \mathrm{mpa}$.

(6)Exhaust Valve That Can Only Slightly Exhaust Air

Big exhaust ports pilling and stop exhausting air under any of the conditions above,only tiny holes exhaust air.

(7)None-Functional Exhaust Valve

Exhaust valve pilling and stop ventilation when air pressure is above $0.02 \mathrm{mpa}$,and no tiny holes work.Practical gas exhaust is almost zero,unsuitable to apply in any pressure pipelines .

\section{Assorted Exhaust Valve's Adaptation on Various Pipelines.}

(1)The $7^{\text {th }}$ kind has no functions.

(2)The $6^{\text {th }}$ kind,tiny holes valve merely fit various air pressured pipelines below DN100.

(3)The $4^{\text {th }}$ and $5^{\text {th }}$ kind of exhaust valves can adapt to relatively short pipelines without ups and downs as well as dramatic ascending,that they are,water pump pipelines or any other possible pressured water pipelines without mixed air and water columns ${ }^{[6]}$. 
(4)The $2^{\text {nd }}$ and $3^{\text {rd }}$ exhaust valves can adapt to medium length pipelines without ups and downs, with only big ascending or descending,but pipeline strength should be big,and diameter should be less than DN1000,can be either water pump or gravity water pipe ${ }^{[7]}$.

(5)The $1^{\text {st }}$ exhaust valve can adapt to a wide range and has good exhaust performance for long distance,big pipe diameter,inverted siphon as well as water pipes with multiple ups and downs.

\section{Current domestic common exhaust valve performance evaluation}

(1)Domestic full pressure high speed exhaust valve is a cylinder type which belongs to the $1^{\text {st }}$ category. Theoretical performance test shows that it is the best choice for the stressful water supply pipe.It can not only exhaust automatically, but also control various exhaust modes to prevent the tube explosion.

(2)The GA type dynamic compound exhaust valve which made in US belongs to the $2^{\text {nd }}$ or $3^{\text {rd }}$ category. As price is expensive,only samples proved and usage is unknown.

(3)The exhaust valve imported from Japan, belongs to the $3^{\text {rd }}$ or $4^{\text {th }}$ category. Each valve hole shall send 6 people in 3 shifts for artificial auxiliary exhaust.

(4)The exhaust valve imported from Israel and most of the well-known domestic enterprises exhaust valve. It belongs to the $4^{\text {th }}$ and $5^{\text {th }}$ category. Commonly referred to as modular or compound exhaust valve. When used, all need to artificial auxiliary exhaust, and some even install the valve after artificial exhausting. Experience has shown that when the delivery way is too long, or more ups and downs, inverted siphon, big diameter, it is easy to get explosion or vapor lock problems when use these valves ${ }^{[8,9]}$.

(5)The exhaust valve of not well-known domestic enterprises. Its structure is not reasonable, so belongs to the $6^{\text {th }}$ or $7^{\text {th }}$ category. Actual measurement shows that the have no exhaust function.

\section{Conclusions}

Through the research to exhaust valve in our experiment,conclusions can be drawn as followed:

(1)Domestic float-ball style vent valves had a generally poor performance,and are unable to exhaust consistently in 0.7mpa,the worst type KP-10 float-ball style exhaust valve start balling-up and stop exhaust under 0.2mpa.The one with best performance also balling-up when the pressure achive several meters of water column.Big exhaust port lost its function after exhaust the first section of air,and can only exhaust minimally through the small exhaustive ports, which can not match up with the air release speed in the pipeline system.Pressured water push air mass and may easily collapse air mass and arouse huge pressure.

(2)Imported float-ball style vent valves has minor differences in performance,basically balling-up appears when water column reaches above 5-7 meters in height.Among them the American dynamic composite exhaust valve has the best performance,which big exhaust ports barely stops exhaust even if water column reaches tens meters high,and with buffering exhaust function.Cannot exhaust smoothly in mixed gas water flow, which design features level is highest in all float-ball style vent valves of its kind.

(3)Cylinder type exhaust valves can buffer vent air at constant speed under any pressure.Expecially good effect on water transmission pipeline with multi-fluctuation and inverted siphon,suitable for complex pipelines of any kind.The exhaust valve closed slowly when exhaust end,which limits the change of water speed in pipeline within $0.3 \mathrm{~m} / \mathrm{s}$ and greatly reduces the water hammer pressure[9] , ensure the safety of the pipeline.

\section{Acknowledgements}

This work is supported by the Xi'an Municipal Science and Technology Bureau of finance, industry university research collaborative innovation program (CXY1518(3)).Chang'an University, key discipline construction projects, Xi'an Aeronautical Institute, the fund support (2015ky1102). 


\section{References}

[1]Jin Z., Jiang N.C., Wang X.H. et al. Stop pump water hammer and protection [M]. second edition. Beijing: Chinese Building Industry Press, 2004: 1, 11-12.“In Chinese”

[2]Naftali Zloczower.Air valves and pressure surge suppression, Valve World, 2011, Vol.16 No.9

[3] Hamman and McCorquodale. air pressure was responsible for lifting manhole covers and blowing up sewerage pipes in Hamilton, Ontario, Canada..1982, Vol.61, 251-256

[4] M. Carlos, Ph.D.,F. J. Arregui, Ph.D., E. Cabrera, M.ASCE, (2011). “Understanding Air Release through Air Valves.” American Society of Civil Engineers.,137, 461-469.

[5]Abreu, J., Cabrera, E., García-Serra, J., and Izquierdo, J. (1992). “Boundary between elastic and inelastic models in hydraulic transient analysis with entrapped air pockets.” Proc., Int. Meeting on Hydraulic Transients with Water Column Separation, E. Cabrera and M. Fanelli eds., Universidad Politécnica de Valencia, 159-179.

[6] Yang Y.S., Wang T. (2005). “Advice on Exhaust Valve Selection Problem in Long-Distance Water Supply Pipe”. J.Water Supply and Drainage Problems. (4),30 32.“In Chinese”

[7] Yang Y.S., Yan M. (2006) “The Best Way to Reduce Cavities Water Hammer and Airbag Exercise Pressor”.J. China Water \& Wastewater. (4),44 47."In Chinese”

[8] Xiong S.Y., Guan X.W., Jin Z.(2003) “ Various Column Separation and Comprehensive Protection of Disconnection Water Hammer Problems and Design Example”. J. China Water \& Wastewater.(7),1 5. “In Chinese”

[9]Yang Y.S., Jin Z.The Calculation Method of Pressurization and Determination on Water-hammer Due to Separate Cavities[J]. Journal of Northwestern institute of Architectural Engineering,1996, (4): 25 30.“In Chinese” 